NASA Technical Memorandum 89881

AIAA-87-9198

\title{
Stress-Life Interrelationships Associated With Alkaline Fuel Cells
}

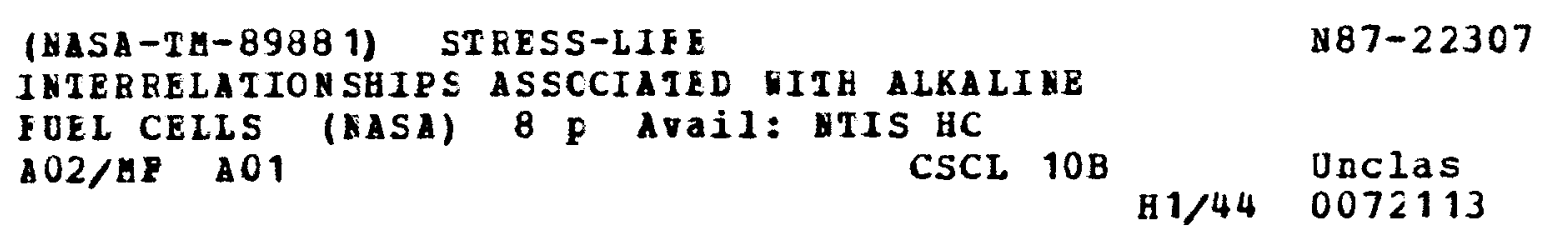

Lawrence $\mathrm{H}$. Thaller

Lewis Research Center

Cleveland, Ohio

Ronald E. Martin and James K. Stedman

International Fuel Cells

South Windsor, Connecticut

Prepared for the

22nd Intersociety Energy Conversion Engineering Conference cosponsored by the AIAA, ANS, ASME, SAE, IEEE, ACS, and AIChE Philadelphia, Pennsylvania, August 10-14, 1987 
STRESS-LIFE INTERRELATIONSHIPS ASSOCIATED

WITH ALKALINE FUEL CELLS

LAWRENCE H. THALLER

National Aeronautics and Space Administration

Lewis Research Center

Cleveland, $\mathrm{OH} 44135$

and

RONALD E.MARTIN

and

JAMES $K$. STEDMAN

International Fuel Cells

South windsor, CT 06074

\section{ABSTRACT}

A review is presented concerning the interrelationships between applied stress and the expected service life of alkaline fuel cells. This paper will confine itself to the physical, chemical, and electrochemical phenomena that take place within the fuel cell stack portion of an overall fuel cell system. A brief review will be given covering the significant improvements in performance and life over the past two decades as well as summarlzing the more recent advances in understanding which can be used to predict the performance and life characteristics of fuel cell systems that have yet to be built.

\section{INTRODUCTION}

Alkaline fuel celis currently serve as the onboard source of electrical power for the space Shuttle. As such, they are the product of an established technology base and an in-place industrial manufacturing capability. This technology has been under development for over twenty years and has undergone several iterations with regard to the system design philosophy, the materials used in the construction of the various cell components, and the general understanding of the performance degradation and failure modes of these devices. This data base, in terms of fundamental and phenomenological understanding of the physical and electrochemical processes, plus the accumulated life test and post test analyses. permit a more accurate prediction of hardware performance and projected useful life by the power system design engineer. It has also permitted the advanced component development efforts to be directed toward the critical components in terms of life and performance. The understanding of the stress-life interrelationships associated with alkaline fuel cells has not only resulted in the improvement of these devices, but can lead to credible projected performance and service life of devices that have not yet been made.

Alkaline fuel cells, as manufactured by International Fuel cells corporation, are referred to as trapped electrolyte cells. As such, each cell is filled with an amount of electrolyte that is not shared with nor is in comunication with any other cell. The sensitivity of this electrolyte to contamination by carbon dioxide has resulted in the development of oxidation resistant materials of construction and the specification of special purity requirements for the reactant gases used for alkaline cells. The effect of carbon dioxide on alkaline fuel cells is detrimental in several ways which will be outlined in more detail in a later section. Suffice it to say here that the technology attack on the problem was two-fold: i) reduce the sources of contamination, and 2) reduce the effect that these contaminants have on the performance and life of an alkaline fuel cell.

This dual-pronged attack over the last several decades has resulted in increases in the expected service life from an early value that was measured in the hundreds of hours, to the Shuttle-vintage technology (currently ten years old) where thousands of hours have been verified via life testing. Advanced technology hardware which incorporates the most recent improvements in materials of construction and catalyst systems, can be projected to have tens of thousands of hours of operation. As more and more life test results and furidamental understanding became available, degradation models and stress versus life interrelationships became more credible. This has permitted trade-offs to be made for the particular mission under consideration. These trade-offs have been factored into a number of potential mission applications resulting in the emergence of alkaline fuel cell systems as a very competitive choice for the power source over a wide spectrum of power levels and mission durations.

\section{THE ALKALINE FUEL CELL}

Figure 1 depicts the general makeup of an alkaline fuel cell of the type under consideration here. An absorbent separator is positioned between two thin catalyzed electrodes. Behind the hydrogen electrode is located an electrolyte reservoir which is partially filled with electrolyte and is in communication with the electrolyte in the other parts of the cell by virtue of the carefully engineered selection of the pore size and wettability 
characteristics of the individual components. The reader is referred to earlier papers for a more

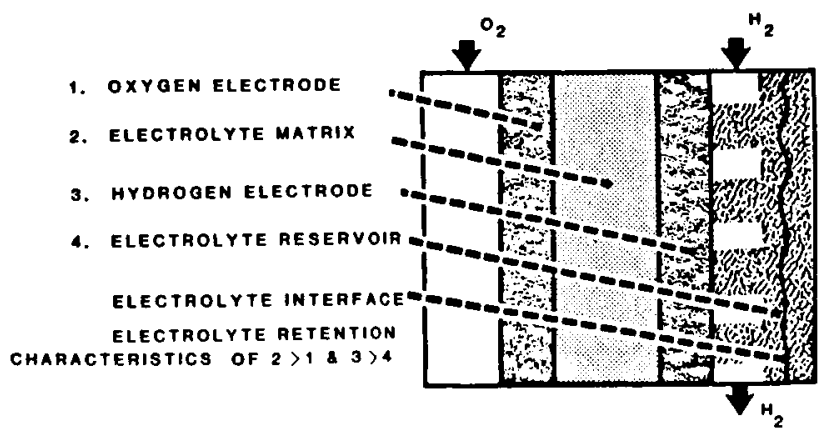

FIGURE 1

FUEL CELL EMPLOYING ELECTROLYTE RESERVOIR

detailed discussion of the pore size engineering aspects of these devices 1,2 . The components of Figure 1 are bonded together and accurately positioned relative to one another by a nonmetallic "picture frame" around the edge. In a completed stack of cells, waste heat is removed by placing cooling plates between cells in the stack at appropriate intervals dictated by the required temperature profiles. A stack of cells and cooling plates is usually connected in a bipolar manner and held together using a series of tie bolts between two end plates.

Product water is removed by circulating an excess amount of hydrogen gas through the cell and then cooling the humid hydrogen gas to the desired dew point. The control of the dew point by the fuel cell system is very critical to the proper operation of the cell and even more critical to the proper operation of the system.

This description of the makeup and operation of an alkaline fuel cell system employing trapped electrolyte has been by necessity very superficial, but it will be fully adequate for the complete understanding of the material that is to follow.

\section{PERFORMANCE DEGRADATION}

In alkaline fuel cells, performance degradation is a function of two main factors, the long-term carbonate contamination of the electrolyte, and electrode stability. Reference 3 addresses the subject of the various consequences on cell performance of electrolytes that become contaminated with carbonates. Equation 1 describes the overall reaction between carbon dioxide and solutions of potassium hydroxide which are used as the electrolyte in these cells:

$$
\mathrm{CO}_{2}+2 \mathrm{KOH}=\mathrm{K}_{2} \mathrm{CO}_{3}+\mathrm{H}_{2} \mathrm{O}
$$

Carbonated electrolytes not only have a lower ionic conductivity compared to pure hydroxide solutions, but also the electrochemical performance of hydrogen and oxygen electrodes is lower ${ }^{3}$.

In addition, carbonated electrolytes have higher vapor pressures than pure caustic solutions ${ }^{3}$. Since the control subsystem is set to a fixed dew point, the electrolyte volume associated with a given dew point is somewhat less after carbona- tion occurs. This characteristic results in a gradual "drying out" of a cell as the electrolyte becomes progressively more carbonated. This particular aspect of the problem was resolved in part by the incorporation of the electrolyte reservoir within the cell4. This reservoir not only permits the cell to accommodate temporary drying or wetting transients encountered during normal operation, but allows for the gradual loss of electrolyte volume during the course of elec. trolyte carbonation. In extreme cases, the actual precipitation of solid material can occur from the solution as the solubility limit is exceeded.

The sources of carbonate contaminants have been found to be carbon-bearing gases $\left(\mathrm{CO}_{2}, \mathrm{CO}\right.$, $\mathrm{CH}_{4}$, etc.) present in the parts-per-million range in the reactant feed streams, as well as the nonmetallic material used as the cell framing material. This material is subject to a very slow rate of oxidation caused by contact with the oxygen reactant gas. This oxidation rate is, of course, temperature and pressure dependent. As will be seen in a later section, constant attention to the carbonation problem has resulted in reactant gas handing procedures and new cell framing materials that have resulted in an ever decreasing significance of this source of performance degradation.

As noted above, long-term electrode stability considerations represent the second class of performance degradation phenomena. At times, electrode stability is associated with the electrocatalyst while at others, it is related to the electrode structure. Electrocatalysts are known to be subject to poisoning, but a more subtle and important set of problems can stem from the very slow changes in electrode performance caused by the recrystallization of the angstrom-sized catalyst particles or the very slow electro-dissolution of the catalyst material itself. Also, within the past few years, it has been found that a very gradual process takes place at the hydrogen electrode that alters its degree of hydrophobicity such that there is a gradual increase in the intrusion of electrolyte into the electrode struc ture. This results in a progressive loss of gas/electrocatalyst interface and thus, lower electrode performance. This has been attributed to the electrophoretic type movement of soluble silicates from the electrolyte matrix into the hydrogen electrode structure ${ }^{5}$.

It is not the intent of this paper to present a complete discussion of this subject. What is important, however, is to know that chemical and electrochemical techniques exist to monitor and measure the important aspects of the electrochemical performance of the hydrogen and oxygen electrodes separately so as to quantitatively assess the contribution of the different sources of the electrode performance degradation process.

over roughly the past two decades, these two groups of phenomena have been under constant scrutiny. What were once sources of great concern have been addressed and solved such that they are no longer matters of prime importance. As one type of performance degradation recedes in importance, a smaller phenomenon previously obscured or overwhelmed by the preceding characteristics now comes more clearly into focus so it too can be addressed and resolved in like manner. 


\section{THE PERFORMANCE DEGRADATION MODEL}

In a very simplistic description, the performance degradation model for an alkaline fuel cell simply represents an effort to chart the effect on cell performance of all the contributors to the two sources of degradation outlined in the preceding section. In itself, this is not a particularly simple task since not only is the state of the technology continually changing to reflect the results of the component improvement efforts, but, more importantiy, the definition of cell or stack failure can be somewhat arbitrary. From experience in the field of single cell testing, it is known that proper multi-cell stack operation becomes statistically unreliable when the average conversion of the hydroxide to carbonate has reached $30 \%$. This is where the cumulative effects of the reduced conductivity, volume and reactivity, as well as possible precipitation at the cell gas inlet all come together in such a manner that among a set of thirty or so cells grouped together in a power plant, one or more cells from this statistical grouping may exhibit erratic performance. This $30 \%$ conversion limit appears to be a sufficient criterion for cell failure; but, at other times, power plant "failure" may be defined as a loss of some number of volts as required by the power electronics of the spacecraft. It should be noted that in both of these definitions of "failure", there is no abrupt failure as such, but only a gradual rate of decay of operating voltage to some predetermined point which may or may not be associated with an incipient catastrophic reduction in performance.

Figure 2 shows the impact on cell performance caused by the accumulating carbonates, as a function of current density. The combined effects of increased electrolyte resistance and reduced electrode performance are included in these data $\mathrm{Col}$ -

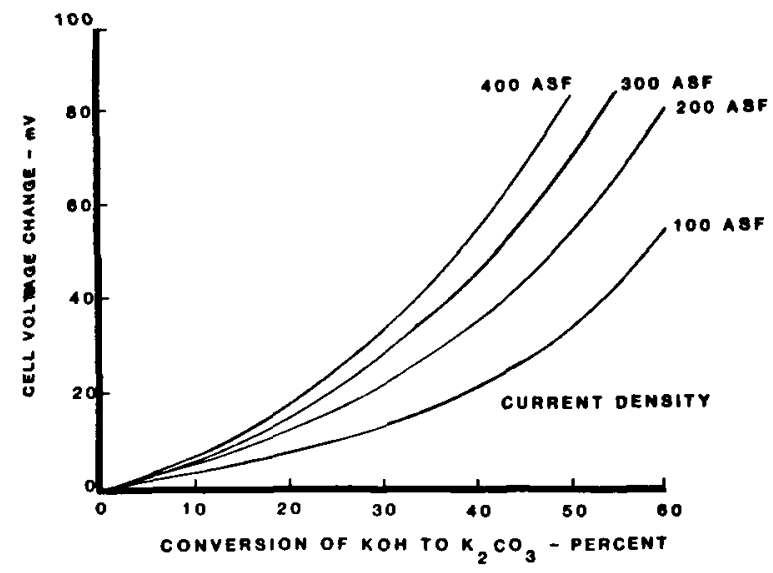

FIGURE 2

EFFECT OF CARBONATES ON CELL PERFORMANCE

lected from cell testing as part of some IFCsponsored work. Since state-of-the-art aerospace power supplies operate in the vicinity of 30 volts, and a fuel cell of the type under discussion operates at about 0.9 volts, a power plant is made up of multiple stacks containing about 32 cells. From Figure 2, if the power plant were operating at a current density of 100 amperes per square foot (ASF) and carbonation were the only degradation mechanism, the $30 \%$ carbonate conver- sion limit would be reached when the overall stack voltage decreased by $0.48 \vee(32$ cells $\times 15 \mathrm{mV} /$ ce11). The length of time required to reach this voltage cutoff depends on several factors.

1. Carbonates due to carbon bearing gases will be proportional to the product of the elapsed time multiplied by the carbon content of the reactant gases times the current density. All other things being equal, life will be inversely proportional to the current density.

2. The carbonates resulting from frame corrosion will depend on the type of framing material used, the temperature of operation of the fuel cell, and to a first approximation, the duration of operation. There appears to be a gradual reduction in the rate of frame oxidation as time goes on. Figure 3 is a summary of the cell frame contribution

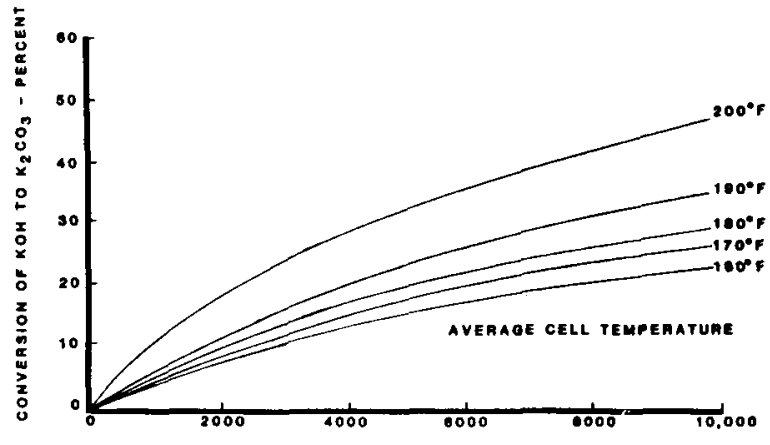

OPERATING TIME - hOUAB

FIGURE 3

EXPECTED CARBONATE FORMATION FOR FIBERGLASS/EPOXY FRAME CELLS

to carbonation in the production space shuttle cell as a function of time for several temperatures of operation. These temperatures all lie within the realm of possibility since acceptable electrochemical performance is not too low at the lower end of the range and the oxidation rate is not too high at the higher end of the range. It is seen from this plot that with the given criterion of $30 \%$ conversion to carbonates within the cell electrolyte, a power plant operating at $200^{\circ} \mathrm{F}$ would have a statistical life capability of 4500 hours, whereas one operating at $160^{\circ} \mathrm{F}$ would have a projected statistical life capability in excess of 10,000 hours. This assumes that all of the performance degradation is caused by carbonate effects. The fuel cells used on the space Shuttle are set to have a coolant inlet temperature of $180^{\circ} \mathrm{F}$ so that the average temperature would be about $190^{\circ} \mathrm{F}$. Several alkaline fuel cell technology improvements, including corrosionresistant cell edge frames and matrices, discussed later, have the potential to extend the statistical life capability of the cell by a factor of fifteen.

Knowledge of factors 1 and 2 help to estimate the amounts of carbonates that are formed, or the percentage conversion of hydroxide to carbonates. The cell design, especially its electrolyte inventory, will determine the overall effect that these contaminants will have on the cell operation. The data from Figure 3 is predicated upon a particular electrolyte inventory that is a function of the thickness of the electrolyte reservoir. At the expense of a thicker, heavier cell, a jonger en- 
durance period could be obtained.

3. Performance losses due to catalyst surface area reductions have been a topic that has received much attention over the years. The reader is referred to the topical reports that have addressed that area of component development $6,7,8$. A general statement on this subject is that in the past, carbonation effects have typically overshadowed the catalyst activity loss. Tafel plots of hydrogen and oxygen half-cell data have been very useful in differentiating between changes in the internal resistance of a cell and the change in the active area associated with either the anode or cathode.

4. Performance degradation due to the reduction of the non-wetting characteristics of the hydrogen electrode is a phenomenon that is detectable only after some five to ten thousand hours of operation. By making a significant change in the anode structure and the type of catalyst system used, significant improvements have been made in this area. This will be discussed more fully in the sections related to component improvements.

The exact degradation model will be a function of the relative significance of the factors outlined above. Some life data as a function of current density collected at a point in time when reactant impurities, cell frame oxidation, and loss of catalyst area were all still contributing factors to the overall performance degradation process are shown in Figure 4 . The data indicate that

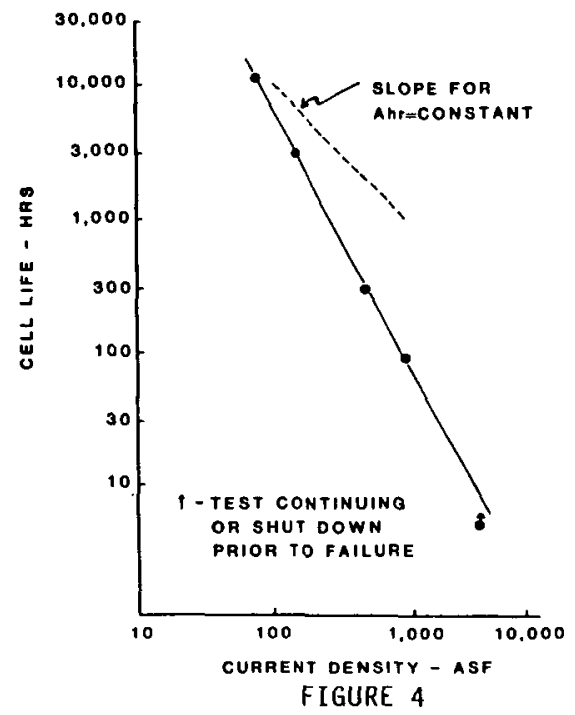

CELL LIFE AS A FUNCTION OF CURRENT DENSITY

the life is inversely related to the square of the current density of operation. Since the time of this early high power density data generated for an Air Force program during the late 1960's and the data obtained from the mid-1970's-vintage cells, there have been several technology improvements incorporated into the cells. These include a process for refining out some of the impurities in the asbestos matrix or replacing this type of separator by the newly developed, more durable butyl rubber bonded potassium titanate matrix. A polyphenylene sulfide cell edge frame with demonstrated oxidation resistance and low cell carbonate formation has been identified. Anode and cathode catalyst layers have been developed for long life. A supported platinum catalyst anode from the commercial fuel cell program has shown improved long-term resistance to electrolyte flooding of the structure. A gold-platinum alloy catalyst cathode with a lower rate of surface area loss due to sintering has been identified. Reliable gold-plated nickel foil cooling plates have also been substituted for silver-plated magnesium plates.

\section{$\checkmark$ STRESS FACTORS}

The relative significance of the various stress factors as they relate to alkaline fuel cell life projections has changed over the years as technology improvements have been incorporated into cell hardware. The various causal relationsiips may be summarized as follows:

Case 1 Performance degradation controlled by external sources of carbonation.

In this case, the current density of operation is the most important stress factor in modeling the cell decay since the incoming gases are the source of the contamination. Historical data as depicted in Figure 4, would suggest that life would be inversely related to the square of the current density, whereas a simple model which integrates the value of the cumulative amp-hours would suggest that the expected service life should be a simple inverse relationship of the first power.

Case 2. Performance degradation controlled by internal sources of carbonation. (Oxidation of carbon bearing materials used in the cell construction).

In this case the temperature of operation is the primary determinant of the useful service life. Life would be reduced at elevated temperatures in accordance with the Arrhenius-type activation energies associated with the oxidation of the cell framing material. Current density would also be a factor, but the integral of the time-temperature factor would be the dominant one.

Case 3. Performance degradation controlled by the loss of catalyst activity.

In this case the stress factor is again temperature related but is compounded by high current density operation where high electrode activity is required. It is assumed here that there are no catalyst poisoning reactions that need to be considered. This type of decay process is also an Arrhenius-type reaction that slows down with time as the catalyst crystallites become progressively larger.

Case 4 . Performance degradation controlled by the loss of the hydrophobic nature of the anode.

In this case operating temperature (corrosion rate of the asbestos material) and the current density will function together as the stress factors. In cases where non-asbestos materials which are not subject to the corrosion characteristics of asbestos are used, this type of problem is not expected to exist.

\section{CURRENT STATUS OF COMPONENT TECHNOLOGY}

The component technologies that have been and 
still are in the process of being upgraded are primarily related to the nonmetallic framing material used to accurately position all of the cell components, the separator material, the catalyst materials and the electrode structures. One component that was not addressed in the preceding sections, but does represent an improvement relative to the Shuttle-type fuel cell is the cooling plate that is made from gold plated nickel foils $5^{9}$. These are to be contrasted with the more traditional ones made from magnesium plates that are first electro-machined to the proper configuration and then electroplated with silver and gold so as to form a protective surface that can withstand extended periods of exposure to potassium hydroxide solutions.

The following sections will compare these advanced components with those that are currently used in state-of -the-art hardware. These comparisons will be in terms of how much better these improved materials are with regard to extending the service life of the respective components, or how much better the improved material is when subjected to a standard evaluation test. These types of comparisons can then be used to develop the performance/life trade offs required to estimate the performance of powerplants that have yet to be built.

\section{SEPARATOR MATERIAL}

Figure 5 shows the results of a standard corrosion test to which candidate separator materials are subjected. The conditions for the test are noted

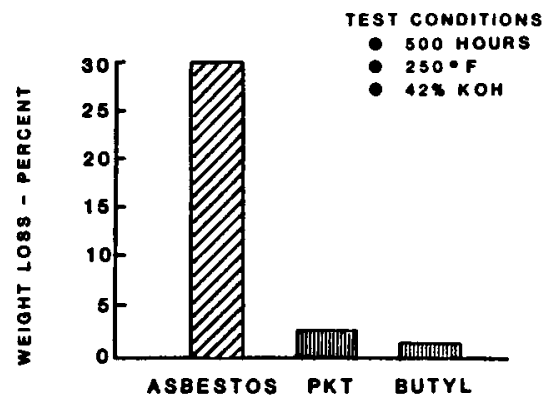

FIGURE 5

CORROSION-CHARACTERISTICS OF ASBESTOS POTASSIUM TITANATE (PDT) AND BUTYL RUBBER

on the figure. Corrosion, of course, is only one factor that is evaluated. others relate to the availability of the material, the handleability of thin $\left(0.010\right.$ to $\left.0.020^{\prime \prime}\right)$ sheets of the material that represent practical separator thicknesses, and, finally, the bubble pressure of the completed mat. The bubble pressure is very important since it not only is a measure of the pore size characteristics of the material, but of the reproducibility of the manufactured mats as well. The pigment-grade potassium titanate (PKT) material bonded together with a small amount of a butyl latex has a greater resistance to corrosion by hot concentrated potassium hydroxide solutions (at the conditions of the test) by a factor of fifteen. It is when asbestos materials are used, that the gradual loss of hydrophobic character of the anode takes place. Careful post-test analysis of cells that had been in operation for 5,000 to 10,000 hours has revealed that the solid deposits which accumulated in the anode consisted primarily of silicons. It was thus concluded that these deposits had originated with the silicate component of the asbestos. This type of deterioration is not expected to be associated with cells constructed from this newer separator material. Test data to date have verified this.

\section{CELL FRAME MATERIAL}

The cell frames used in the Shuttle-type cells are made from a high quality epoxy/fiberglass material with excellent dimensional stability. It is, however, subject to slow attack by oxygen at the elevated temperatures used in operating fuel cells. The potassium hydroxide also attacks the fiberglass component of the plastic composite.

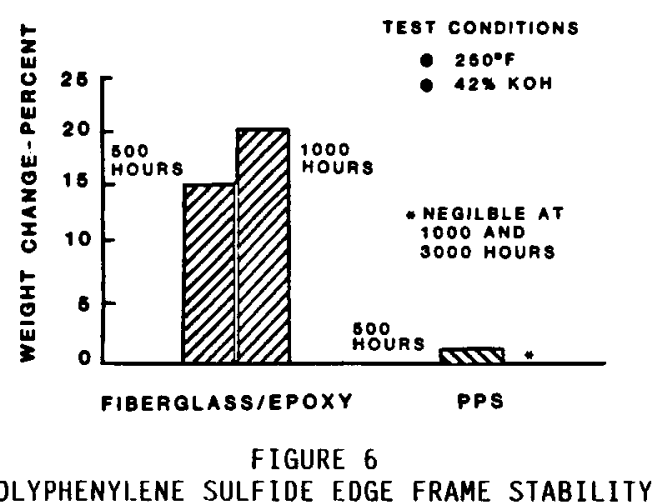

Figure 6 depicts the relative stabilities of framing materials, measured by a standardized corrosion test in the presence of oxygen under the conditions noted. Since the weight loss is proportional to the subsequent carbonate formation in the cell, the fifteen-fold increase in the stability of polyphenylene sulfide over fiberglass/epoxy would be expected to correspond to an equivalent extension of the useful life of the cell. From Figure 2, it is seen that at low current density operation (100 ASF) a carbonate related performance loss of 15 millivolts corresponds to the $30 \%$ limit of conversion to carbonates. From Figure 3 , this $30 \%$ conversion would be expected to occur after 10,000 hours of operation at $180^{\circ} \mathrm{F}$, providing the incoming gases were completely free of carbon-bearing gases. This 10,000 hours of operation using state-of-the-art components could be projected to 150,000 hours using the improved frame material. Alternatively, one could sacrifice some projected life in order to reduce the weight of the powerplant by increasing the current density to $400 \mathrm{ASF}$ and the operating temperature to $200^{\circ} \mathrm{F}$ where the catalysts would be more reactive. The trends in projected reduction in service life with increasing temperature not only have to take into account the increased frame corrosion characteristics from plots similar to figure 3 , but would also have to take into account the effects on the catalyst stability to be outlined in the next section.

\section{ANODE CATALYST AND STRUCTURE}

Figure 7 shows the results of life testing an improved electrode structure that incorporated a new catalyst system. The advanced anode structure takes advantage of the catalyst work performed 


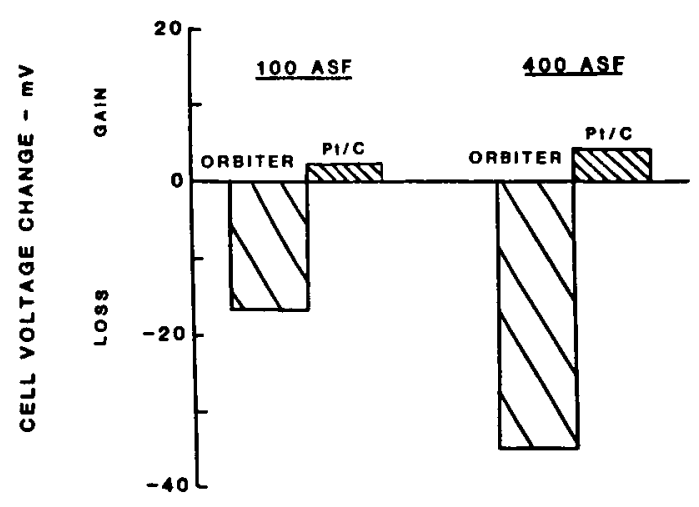

FIGURE 7

ANODE CATALYST PERFORMANCE CHARACTERISTICS FOLLOWING 5000 HOURS OF TESTING

in the phosphoric acid programs where crystallite stability is much more critical. Platinum particles are supported on a carbon substrate. More traditional electrode structures are made from a mixture of catalyst alloy particles and teflon emulsions to develop the proper degree of hydrophobicity. The advanced electrodes are made with a higher degree of hydrophobicity in anticipation of a gradual increase in the wetting character during the course of operation in the cases where asbestos separator material is used. These data were collected after about 5000 hours of operation and the loss (or gain, in the case of the advanced electrodes) at 100 and 400 ASF operation is noted. The greater performance loss at higher current densities is indicative of the increase in the wetting character (increased diffusional losses associated with hydrogen) of the electrode. The slight improvement in the performance of the advanced electrode with time results from a gradual increase in the wetting character of the electrode to a more optimal condition. With a non-asbestos material, a more stable performance level with time would be expected.

\section{CATHODE CATALYST AND STRUCTURE}

The cathode catalyst used in state-of-the-art alkaline fuel cells is a powdered form of a goldplatinum alloy that is mixed with a tefion emulsion. This mixture is then spread onto a fine mesh screen and heated to the point where the teflon begins to sinter. This electrode structure is a significant improvement over one that used a platinum-palladium alloy, in terms of operating cell voltage and the rates of electro-oxidation and recrystallization 7 . The rate of loss of electrode performance due to recrystallization is such that a 15 millivolt loss would be expected to take place over a 150,000 hour period of time. Electrochemical techniques can measure the active surface area of electrode structures rather accurately, and these measurements can then be used to predict performance over such long time frames. These projections are rather straightforward and have been verified in analogous situations. The projected performance degradation characteristics of both the anode and the cathode at $180^{\circ} \mathrm{F}$ operation is such that when the 15 millivolt cutoff due to carbonate effects is reached, the anode and the cathode will each have lost a similar amount, for a total loss of about 50 millivolts loss after 150,000 hours of operation at 100 ASF.

\section{CONCLUDING REMARKS}

Component development efforts directed toward increasing the life and performance of alkaline fuel cells have resulted in single cell hardware that can be projected to have a service life beyond 100,000 hours, if the reactant gases are maintained scrupulously free of any carbon bearing gases. This service life is well beyond most missions where fuel cells could potentially be of value. Life vs performance trades thus can be carried out with a reasonable degree of accuracy using the well-documented performance degradation models that have been establish through a long term program of life testing and post test analysis. The relative effects on service life of different forms of stress are presented so that mission planners can, to a first approximation, establish the merits of alkaline fuel cells for the various advanced missions.

\section{REFERENCES}

1. Abbey, K. M.; and Thaller, L. H.: Pore Size Engineering Applied to Starved Electrochemical Cells and Batteries. Proceedings of the 17 th Intersociety Energy Conversion Engineering Conference, vol. 2, IEEE, 1982, pp. 757-764.

2. Thaller, L. H.: A Flooded-Starved Design for Nickel-Cadmium Cells. J. Power Sources, vol. 18, nos. 2-3, Aug.-Sept. 1986, pp. 161-167.

3. Thaller, L. H.; Post, R. E.; and Easter, R. W.: Effects of Carbon Dioxide on Trapped Electrolyte Hydrogen-0xygen, Alkaline Fuel Cells. Proceedings of the 5 th Intersociety Energy Conversion Engineering Conference, American Nuclear Soclety, 1970, pp. 5-72 to $5-79$.

4. Stedman, J. K.; and Bushnell, C. L.: MatrixType Fuel Cell. U.S. Patent No. $3,779,811$, DeC. 1973.

5. Martin, R. E.: Advanced Technology Lightweight Fuel Cell Program. (FCR-3045, United Technologies Corp.; NASA Contract NAS3-21293) NASA CR-165417, 1981, pp. 24,27.

6. Grevstad, P. E.: Development of Advanced Fuel Cell system. (PWA-4542, Pratt and Whitney Aircraft; NASA Contract NAS3-15339) NASA CR-121136, 1972.

7. Handley, L. M.; Meyer, A. P.; and Bell, W. F.: Development of Advanced Fuel Ce11 System, Phase 2. (PWA-4984 Pratt \& Whitney A1rcraft; NASA Contract NAS3-15339) NASA CR-134721, 1973.

8. Handley, L. M.; Meyer, A. P.; and Bell, W. F.: Development of Advanced Fuel Cell system, Phase 3. (PWA-5201, Pratt \& Whitney Air craft; NASA Contract NAS3-15339) NASA CR-134878, 1975.

9. Martin, R. E.: Advanced Technology Lightweight Fuel Cell Program. (FCR-3045, United Technologies Corp.; NASA Contract NAS3-21293) NASA CR-165417, 1981, pp. 24,25. 


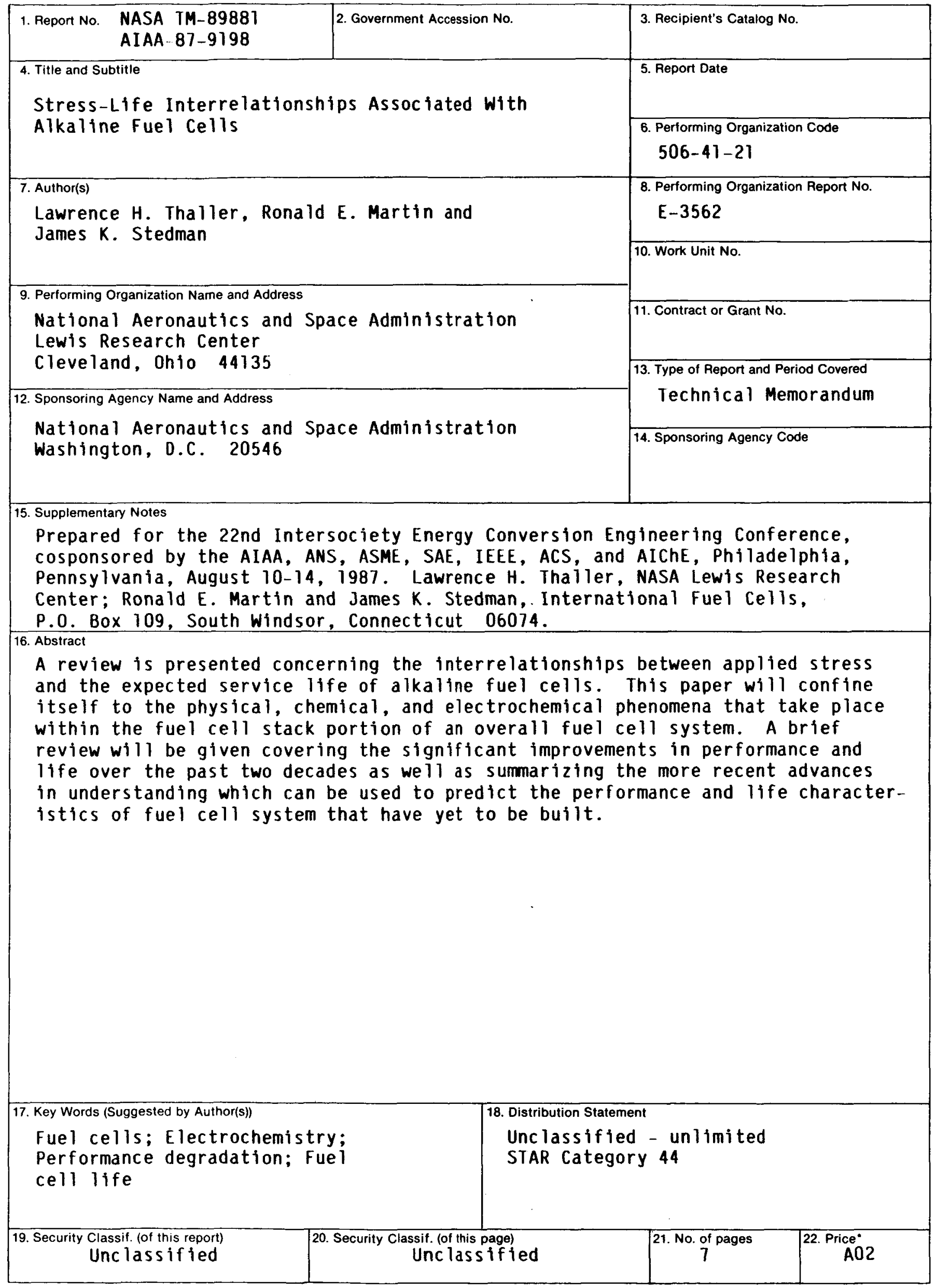

